$1 \cdot 9$

دراسة اقتصادية لتقييم اداء اهم مشروعات التصنيع الزراعي في محافظة الفيوم

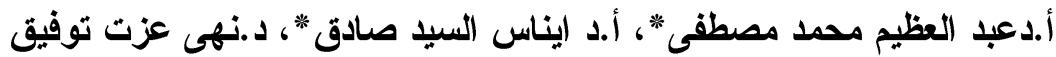

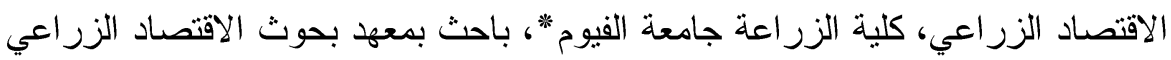

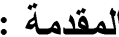

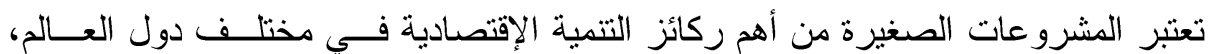

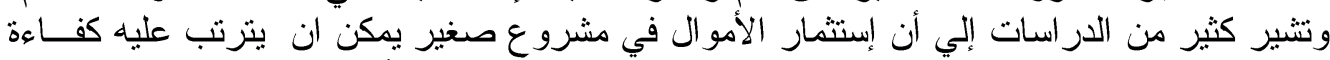

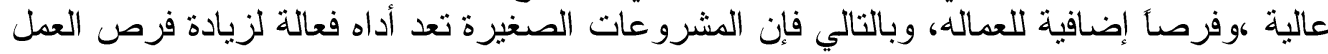

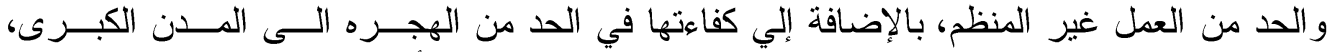

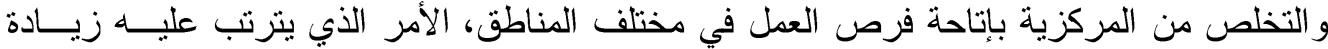

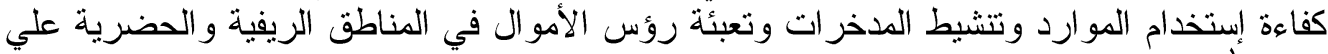

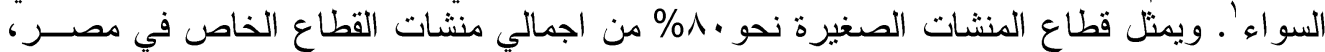

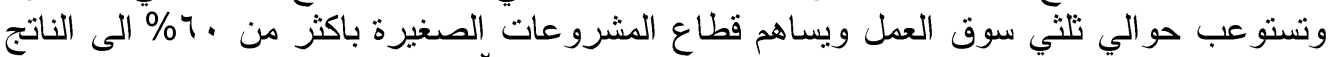

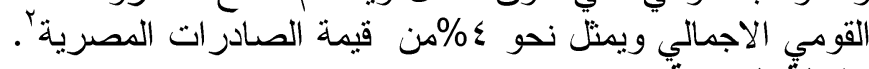

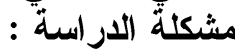

تو اجه الدولة منذ سنوات ظروفاً غير اقتصاديه تتمثل في زيادة معدل النمو السكاني وزيادة النياة

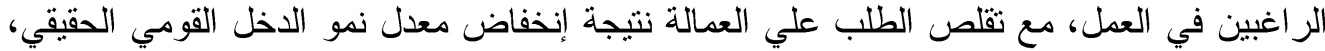

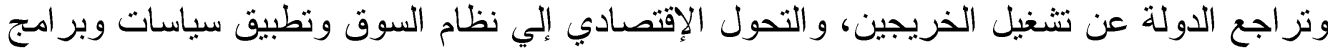

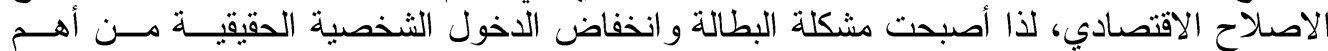

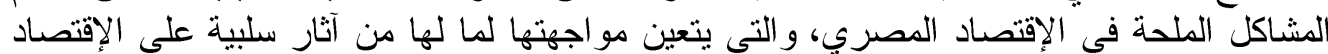

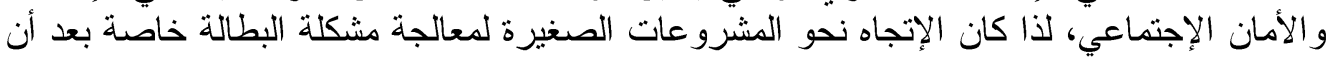

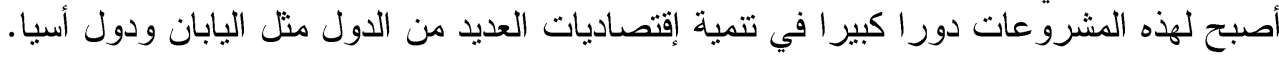

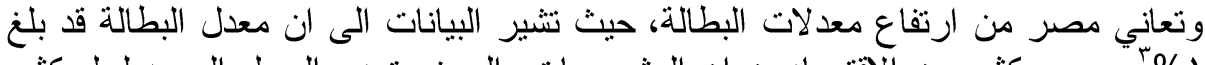

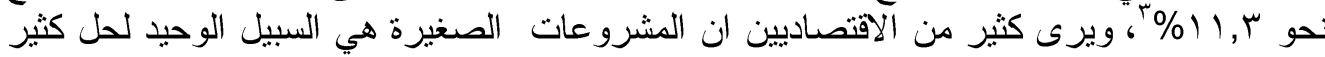

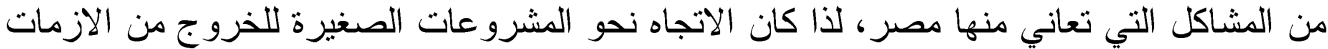

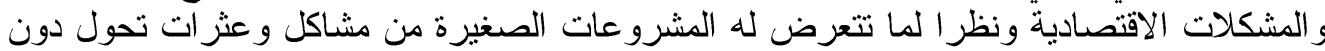

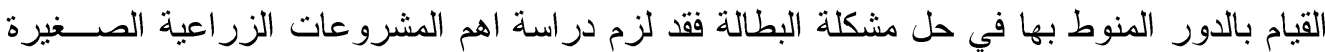

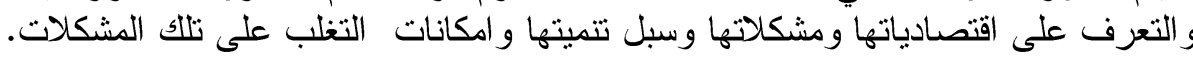

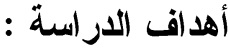

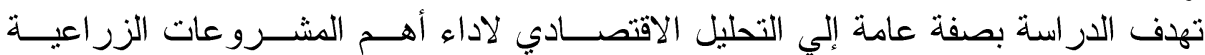

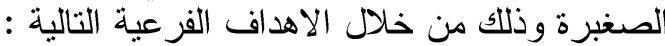
1- الثقييم المالي لالهم المشروعات الصغيرة بمحافظة الفيوم باستخدام المعايير المخصومة و غيـر

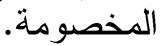

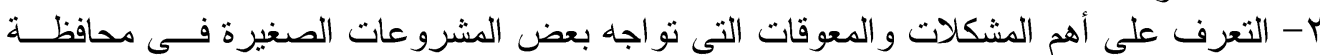

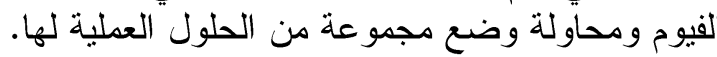

المجالس القومية المتخصصة: تُجيع وتتمية المشروعات الصغيرة، تثرير المجلس القومي للذدمات والتتمية الاجتماعية، الدورة

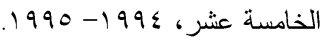

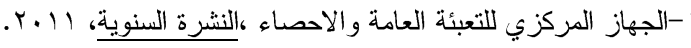

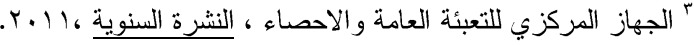

Fayoum J. Agric. Res. \& Dev., Vol. 29, No.2, July, 2015 
11.

الطريقة البحثية ومصادر البيانات :

اعتمدت الدراسة على أساليب التحليل الاقتصادي الوصفي و الكمي اللازم لتحليل البيانات،

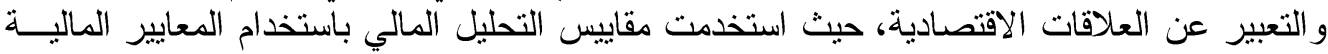

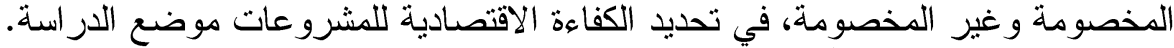

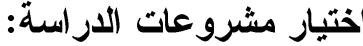

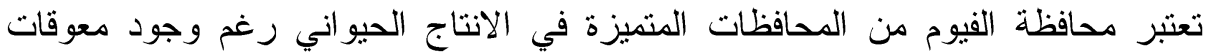

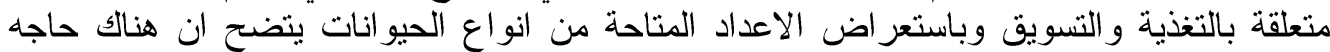

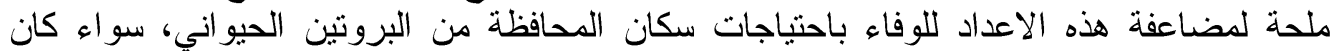

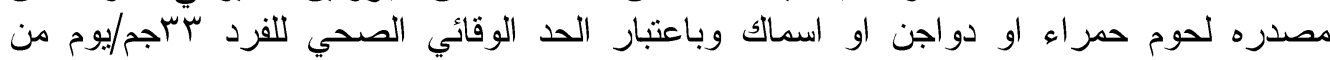

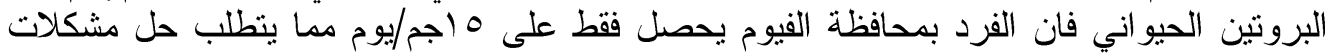

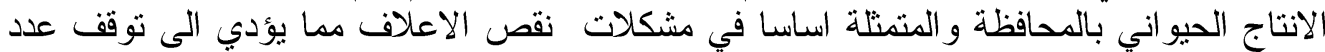

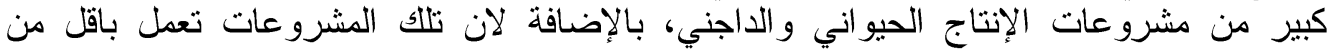

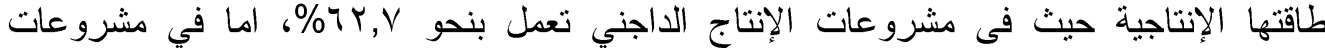

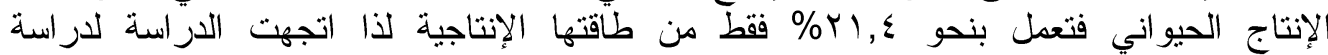

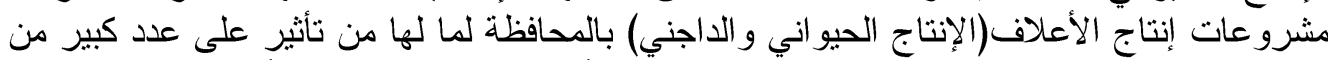

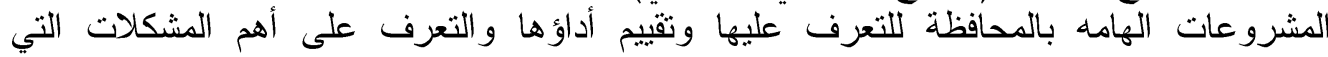

كما تبين ان محصول الزيتون هو محصول الفاكهة الاول في المحافظة حيث تمنل تو اجهها.

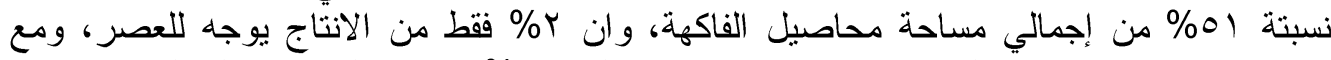

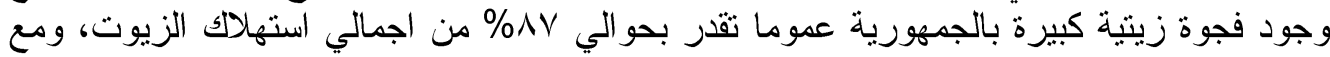

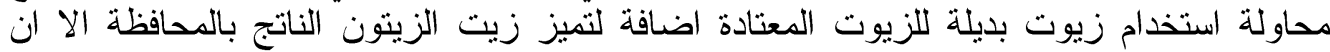

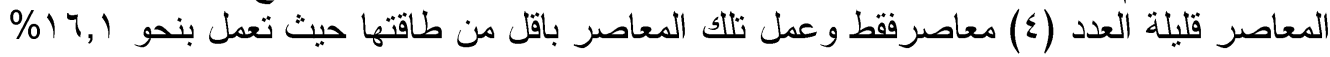

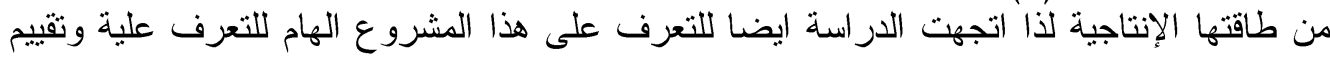

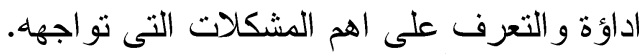

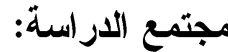

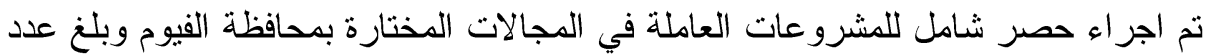

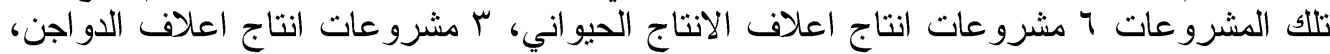

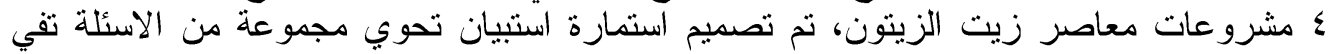

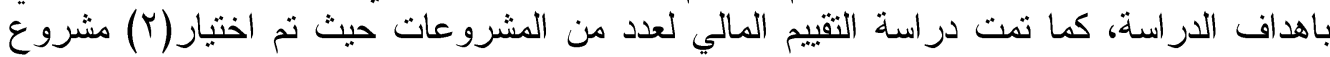

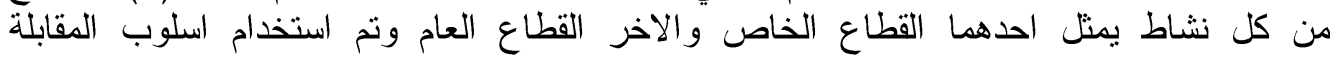

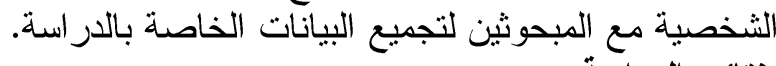

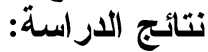

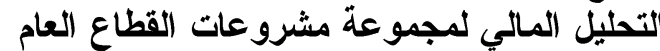

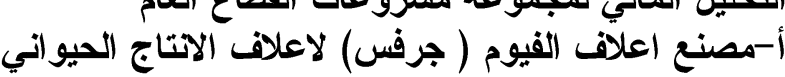

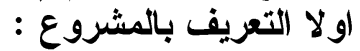

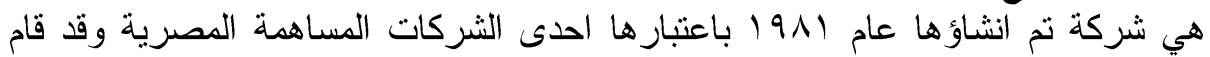

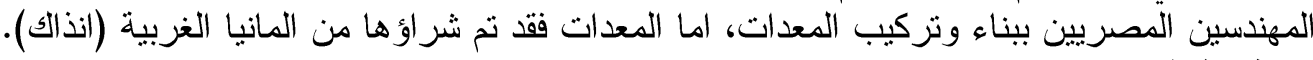

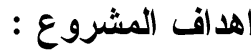

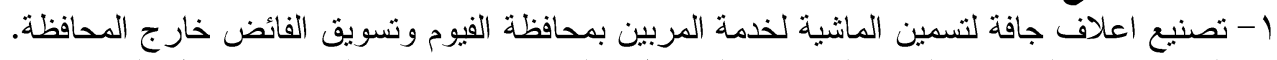

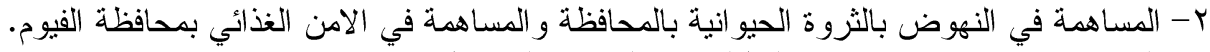
r- المساهمة في تخفيض معدلات البطالة بتشغيل ابناء المحافظة.

Fayoum J. Agric. Res. \& Dev., Vol. 29, No.2, July, 2015 
111

تكاليف واير ادات واربحية تصنيع الاعلاف بمصنع العلف بجرفس .

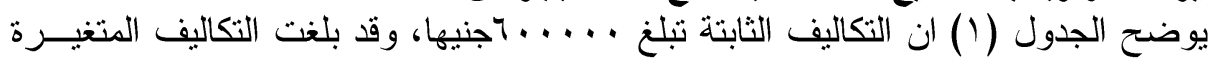

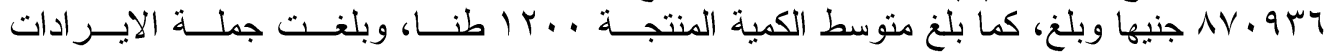

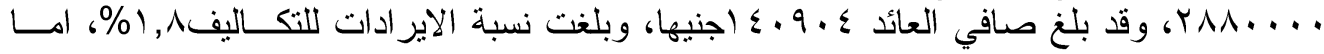

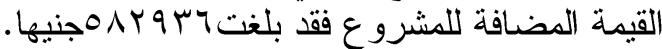

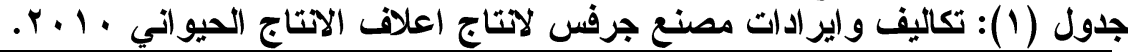

\begin{tabular}{|c|c|}
\hline القيمه بالجنيه & البيان \\
\hline $7 \ldots \ldots$ & التكاليف الثابتة \\
\hline NV.qM & التكاليف المتغيرة \\
\hline $1 \leqslant V .9 \mu q$ & اجمالي التكاليف الكلية \\
\hline Ir.. & متوسط الكمية المنتجة \\
\hline$r \leqslant \ldots$ & متوسط سعر بيع الطن \\
\hline rAA.... & اجمالي الاير ادات \\
\hline $1 \leqslant \cdot 9 \cdot \varepsilon$ & صافي العائد \\
\hline 1.1 & نسبة الاير ادَات/ التكاليف \\
\hline OAYqMY & القيمة المضافة \\
\hline
\end{tabular}

التسويث : (1)

يتم التسويق عن طريق منافذ المشروع التي تبلغ ثلاث منافذ منها ما يصل للمستهلك مبانشرة ومنها ما يصل عن طريق تجار التجزئة.

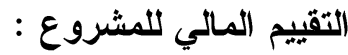

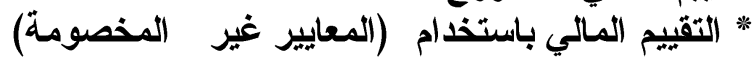

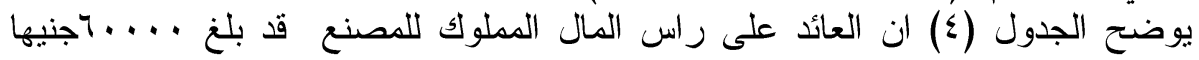

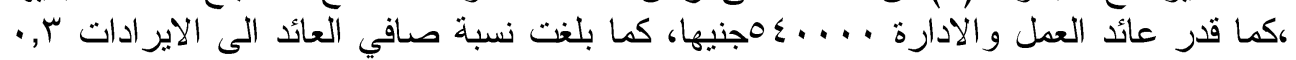

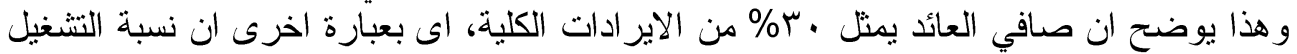

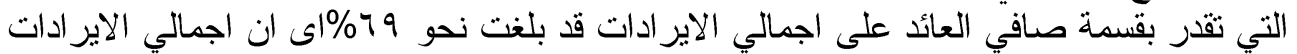

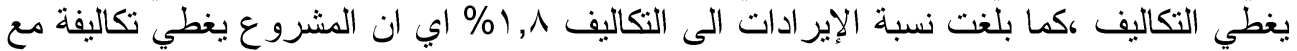

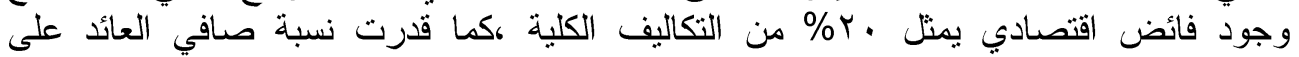

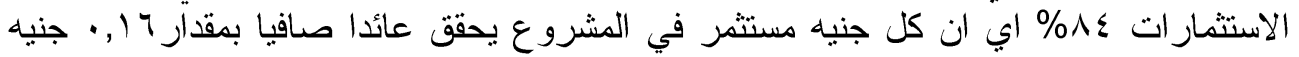

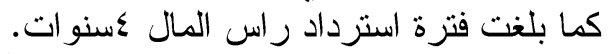

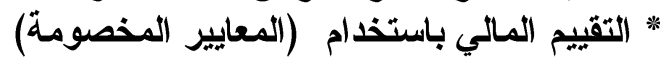

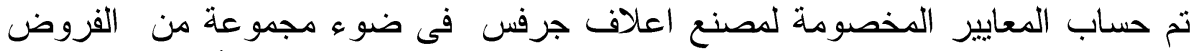
اهمها ان العمر المقدر للمشروع هو خمسة عشر عاما وذلك بناءا على العمر الأفتراضى اضى للاعلات

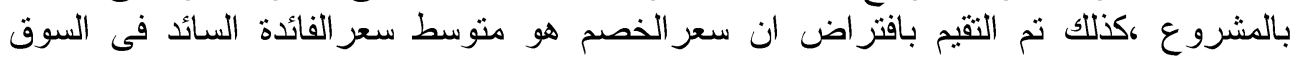

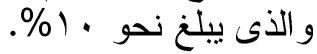

وباستعر اض بيانات الجدول (0) يتضح ان نسبة المنافع الحالية الى التكاليف الحالية

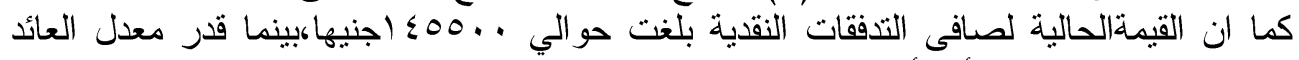

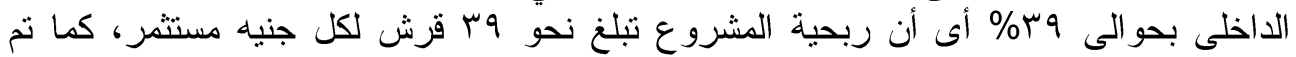

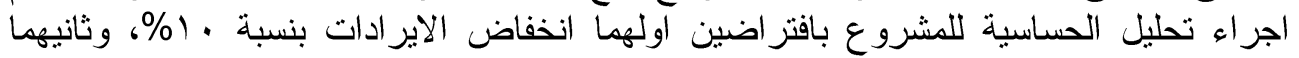

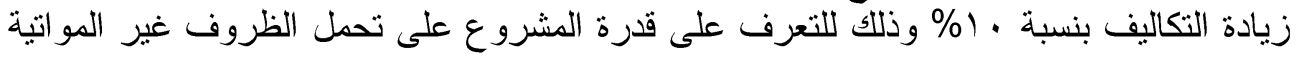

Fayoum J. Agric. Res. \& Dev., Vol. 29, No.2, July, 2015 
$11 \mathrm{r}$

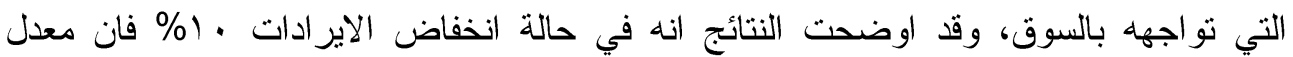

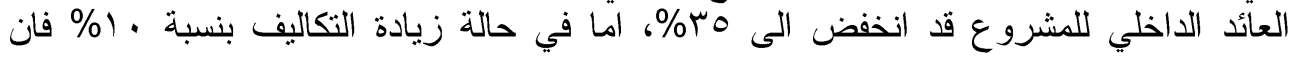

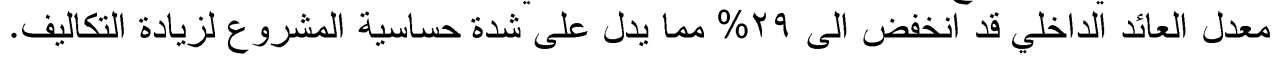

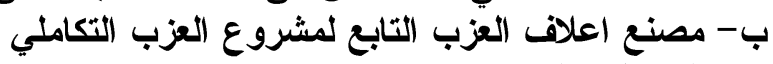
اولا التعريف بالمشروع : الافئ

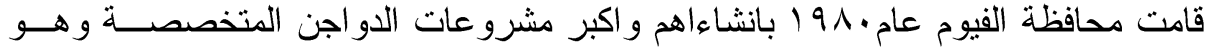

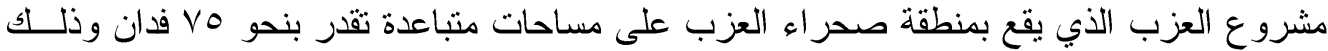

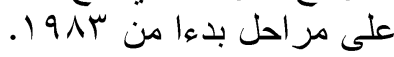

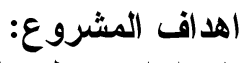

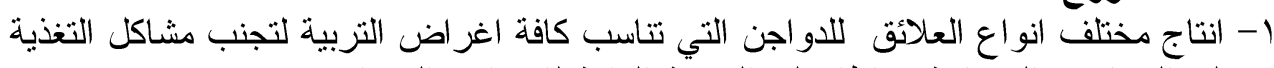

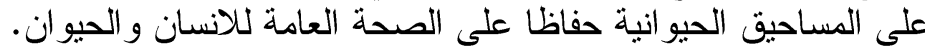

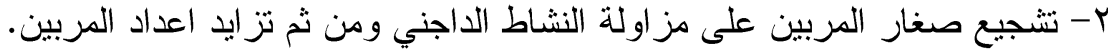

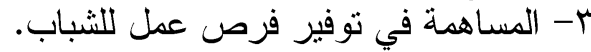

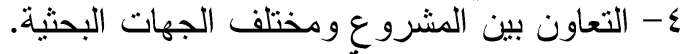

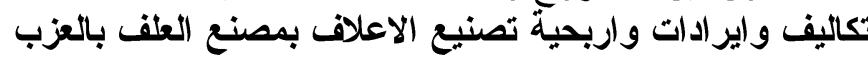

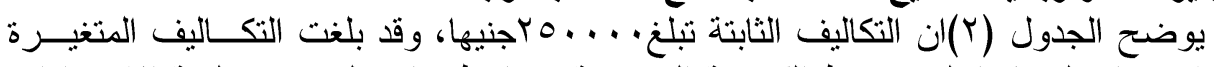

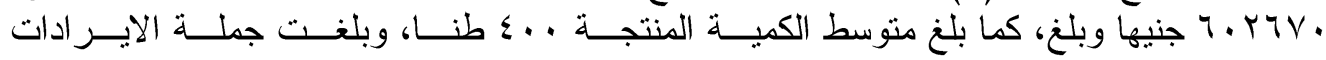

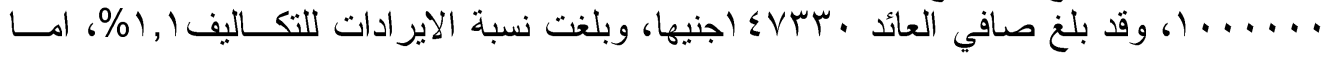

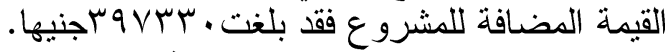

\begin{tabular}{|c|c|}
\hline القيمه بالجنيه & البيان \\
\hline ro.... & التكاليف الثابتة \\
\hline Y. YTV. & التكاليف المتغيرة \\
\hline NOYTV. & اجمالي التكاليف \\
\hline$\xi \ldots$ & متوسط الكمية المنتجة \\
\hline Yo.. & متوسط سعر بيع الطن \\
\hline$\ldots \ldots$ & اجمالي الاير ادات \\
\hline IEVTr. & صافي العائد \\
\hline 1.1 & نسبة الاير ادات/ التكاليف \\
\hline rqVRr. & القيمة المضافة \\
\hline
\end{tabular}

التسويق الى المحطات وذلك حسب كل محطة واحتياجاتها الجزء المتبقي من الانتاج يسوق عن طريق منافذ المشروع ويوجد 1 منافذ للمشروع لتسويق المنتجات.

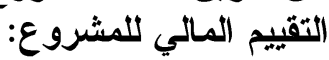

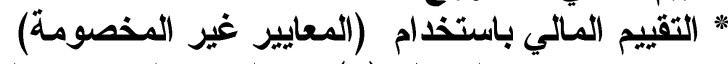

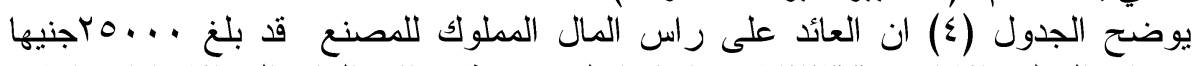

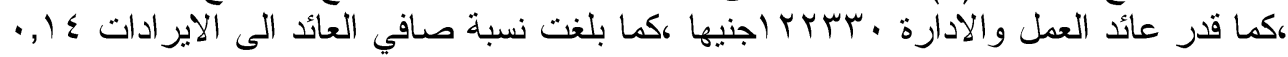

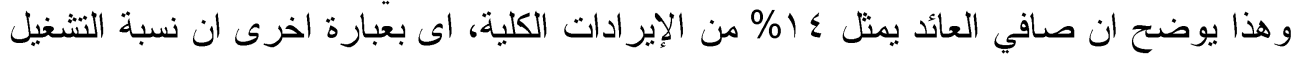

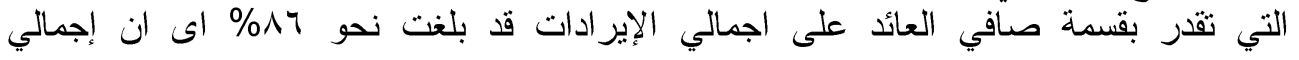

Fayoum J. Agric. Res. \& Dev., Vol. 29, No.2, July, 2015 


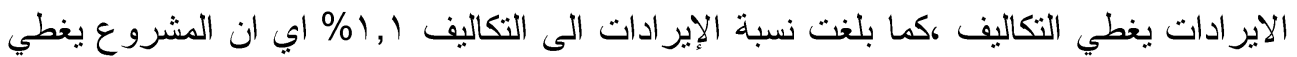

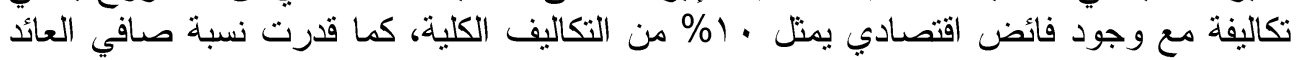

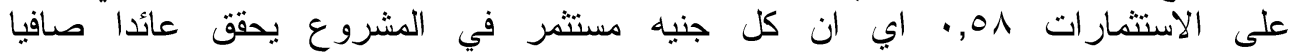

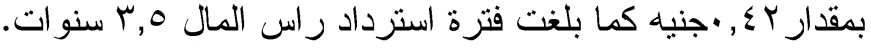

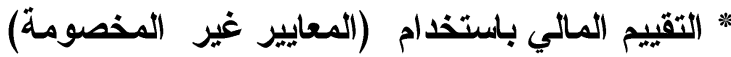

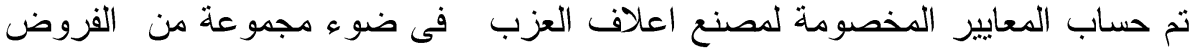

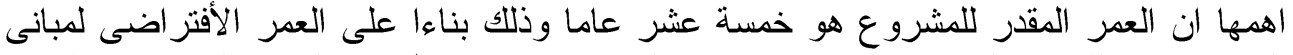

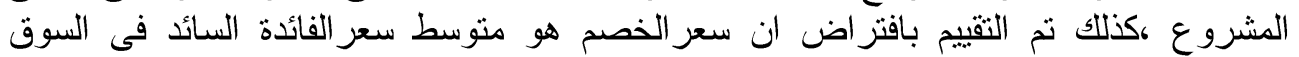

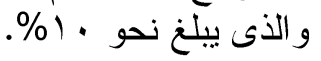

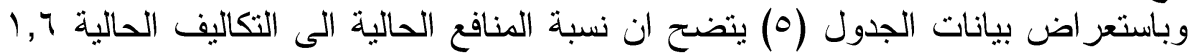

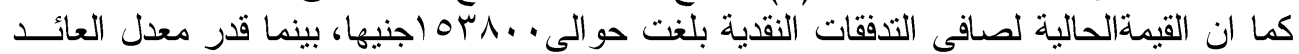

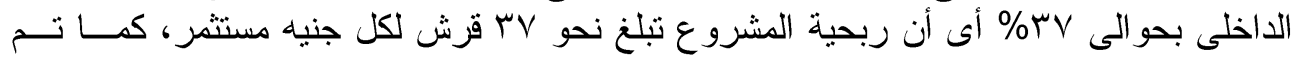

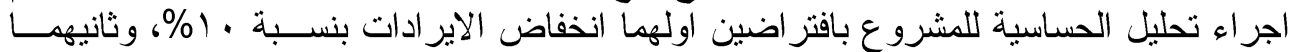

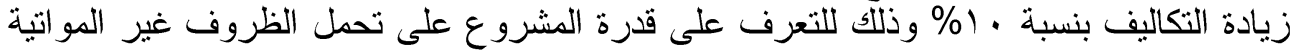

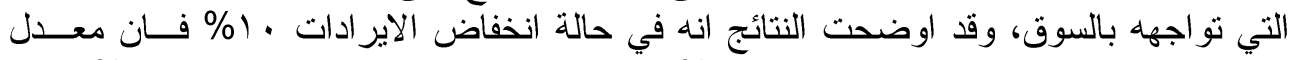

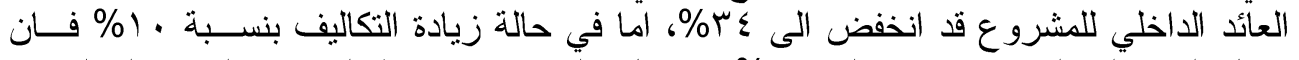

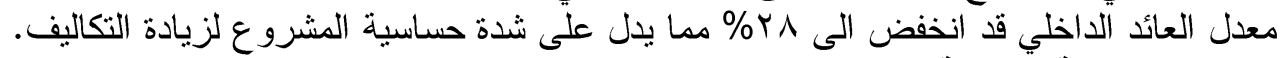

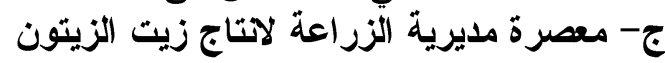

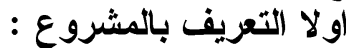

قامت مديرية الزر اعة بالفيوم عام 1917 بانشاء معصرة لزيت الزيتون على مساحة تبلغ • مب متر ا داخل مبنى مديرية الزر اعة اعلة.

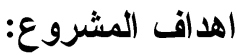
1- يهدف المشروع العمل على توفير زيت الزيتون بالمحافظة وذلك لتميز المحافظة في انتاج

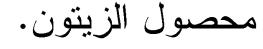

r- r- توفير العمل لعدد من ابناء المحافظة.

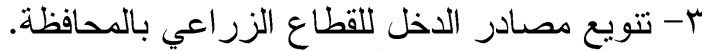

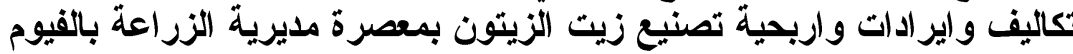

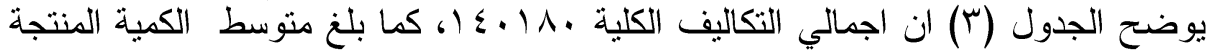

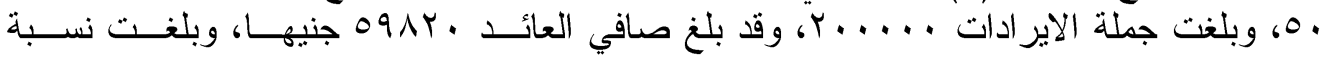

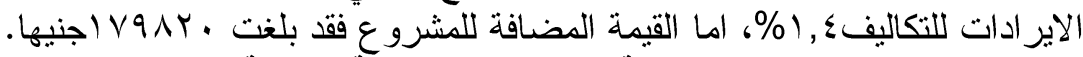

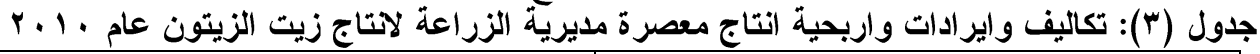

\begin{tabular}{|c|c|}
\hline القيمه بالجنيله & البيان \\
\hline $1, \ldots \ldots$ & التكالف الثابتة \\
\hline$r \cdot 1 \Lambda$. & اجمالي التكاليف المتغيرة \\
\hline $1 \varepsilon \cdot 1 \wedge$. & اجمالّي التكاليف الكلية \\
\hline . 0 (طن) & متوسط الكمية المنتجة \\
\hline$\{\ldots$ & منوسط سعر بيع الكيلو \\
\hline r..... & الجمالي الاير ادات \\
\hline O9Ar. & صافي العائد \\
\hline $1 . \varepsilon$ & نسبة الاير ادات/ التكاليف \\
\hline IVGAY. & القيمة المضافة \\
\hline
\end{tabular}

Fayoum J. Agric. Res. \& Dev., Vol. 29, No.2, July, 2015 
$11 \varepsilon$

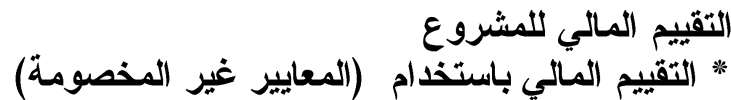

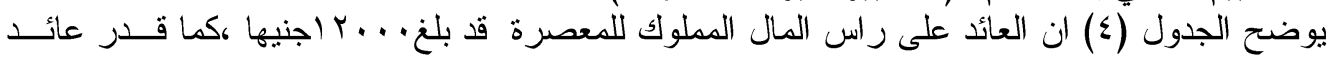

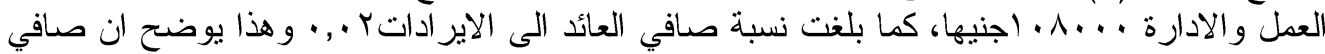

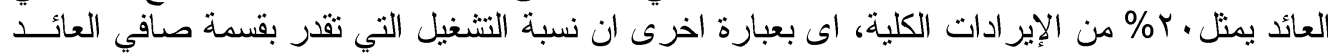

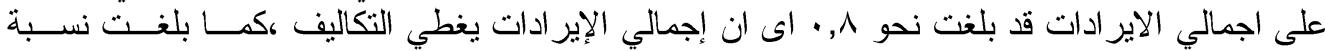

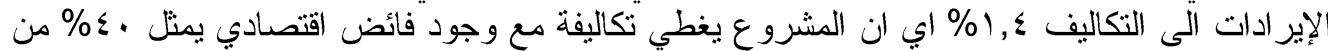

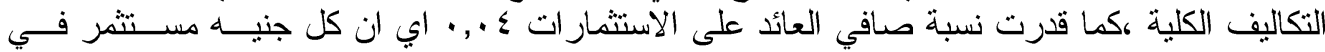

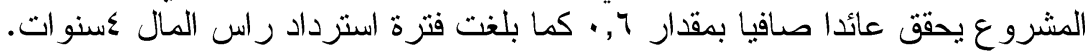

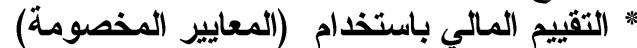

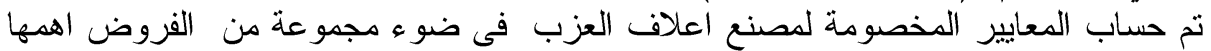

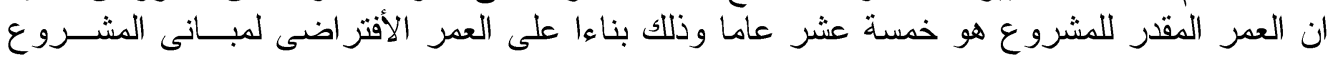

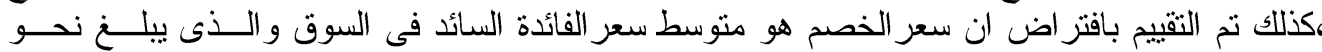
$\% 1$.

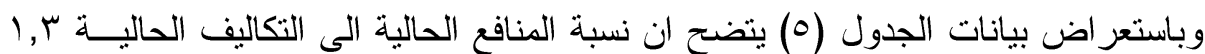

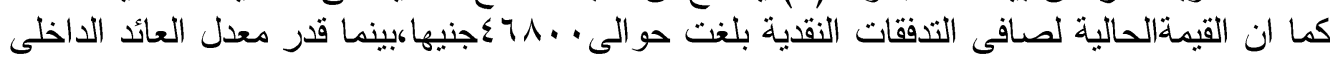

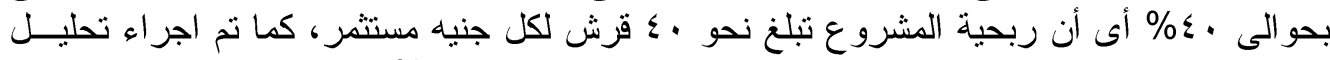

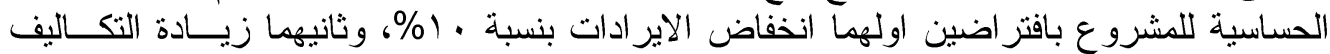

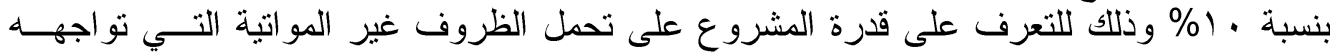

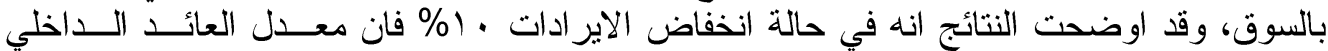

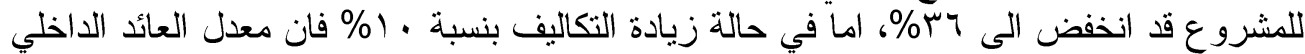

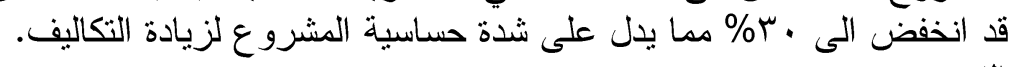

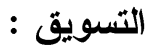

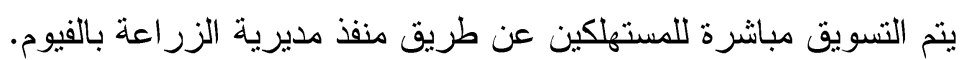

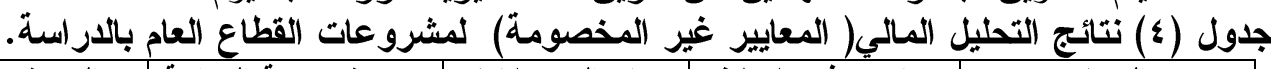

\begin{tabular}{|c|c|c|c|c|}
\hline الوحدة & معصرة مديرية الزراعة & مصنع العزب لآتاج & مصنع جرفس لاعلاف الحيو اني & المعيار \\
\hline الجنية & $1, \ldots$ & ro... & $7 \ldots$ & العائد على راس المال \\
\hline الجنية & $1,1 \ldots$ & ITYMT. & $0 \varepsilon \ldots$ & عائد الادارة \\
\hline$\%$ & $\ldots Y$ & $. .1 \leqslant$ & $\ldots \leqslant$ & نسبة صافي العائد الى الى العات \\
\hline$\%$ & $\ldots \wedge$ &. .10 &. .01 & نسبة التتشغيل \\
\hline$\%$ & $1 . \varepsilon$ & 1.1 & 1.1 & نسبة الاير ادات للتكاليف \\
\hline$\%$ & $\ldots \varepsilon$ &. .01 & $\ldots 1$ & العائد على الاستثمار \\
\hline السنة - ل السنة & $\varepsilon$ & r.o & $\varepsilon$ & فترة الاسترداد \\
\hline
\end{tabular}

Fayoum J. Agric. Res. \& Dev., Vol. 29, No.2, July, 2015 
110

\begin{tabular}{|c|c|c|c|c|}
\hline \multicolumn{2}{|c|}{ (ألبيان } \\
\hline
\end{tabular}

ب- اهم المشكلات بمشروعات القطاع العام المثرات

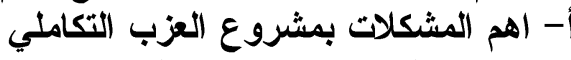

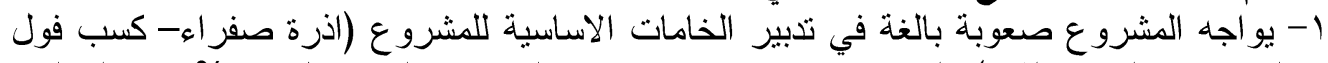

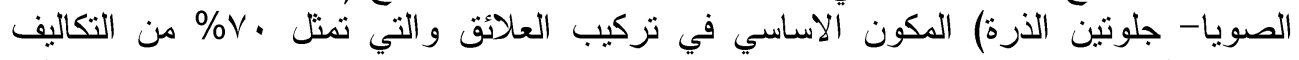

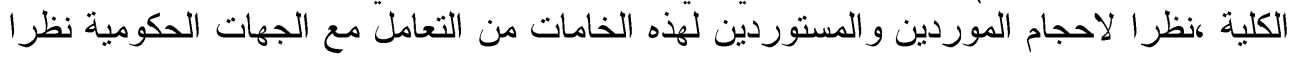

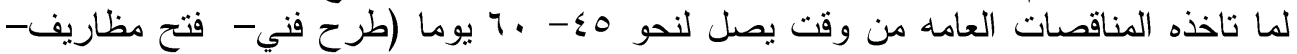
بت مالي- تعاقد).

r- الصعوبة في تدبير ميز انيات للاحلال و التجديد مما يؤثز على العملية الانتاجية.

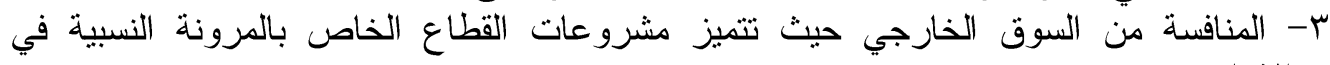
الانتاج.

ع- ارتفاع اسعار الخامات نظر ا للاعتمادعلى الاستير اد.

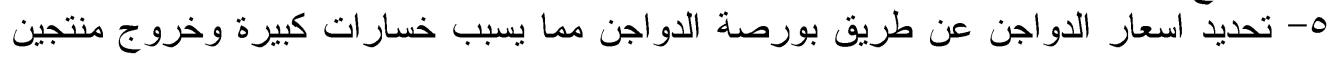
من السوق مما يؤثر على الطلب. צ- ارثفاع اسعار الغاز يؤدي لخروج الكثير من الصناعة حيث تعمل المزارع باقل من طاقتها الانتاجية. - V التذبذب في اسعار الكتاكيت يؤثز على الحجوم الانتاجية للمزارع، مما يؤثر بالتبعية على الطلب على العلف.

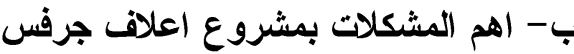
ا- الصعوبة البالغة في تدبير الخامات الاساسية نظرا للتعقيدات الحكومية بسبب نظام التهات المناقصات

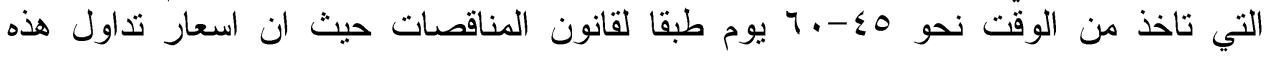

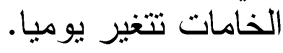
r- ارتباط التمويل بالتمويل الحكومي فقط و عدم القدرة على زيادة مصادر التمويل.

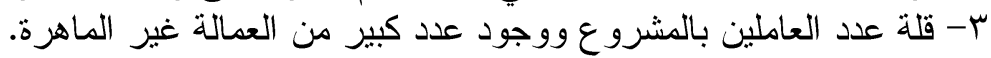
ع- التسويق بالنظام الاجل في عدد من مشروعات القطاع الحكومي مدا يؤثر على استمرار العملية الانتاجية. 0- عدم توفر التمويل اللازم لعمل عمليات الاحلال و التجديد بكفاءة. ؟- التعقيدات الروتينية في جميع مر احل الانتاج و التسويق. - V المنافسة من السوق الخارجي حيث تتميز مشروعات القطاع الإع الخاص بالمرونة النسبية في Fayoum J. Agric. Res. \& Dev., Vol. 29, No.2, July, 2015 
117

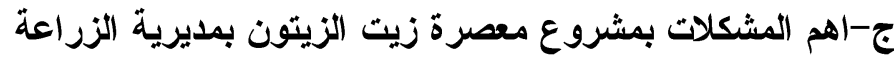

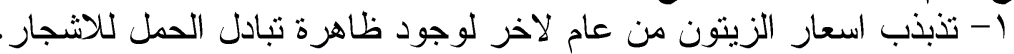

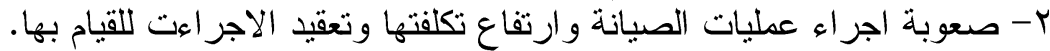
ب- محدودية راس المال اللازم للتوسع في التانة الانتاج.

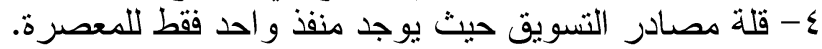

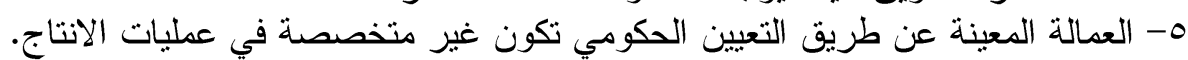
7- احتكار التجار لتجارة الزيتون وزيته التهينه بالمحافظة.

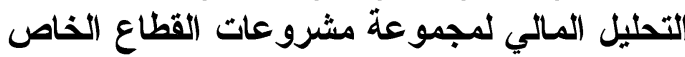

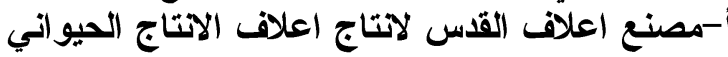
اولا التعريف بالمشروع : التاني

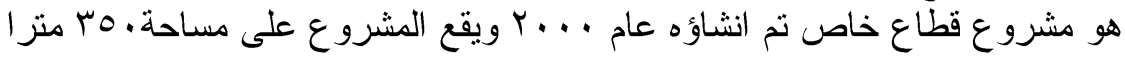
بالمدينة الصناعية بكوم اوشيم.

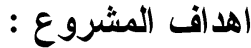

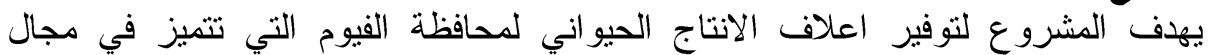

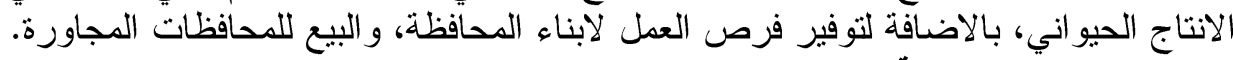

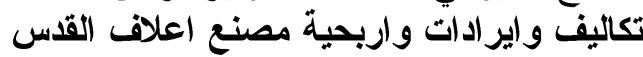

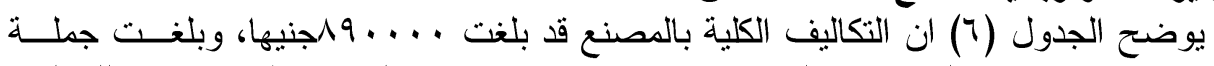

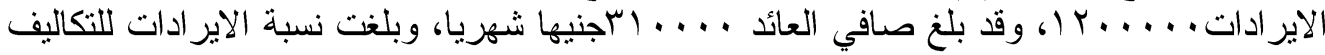

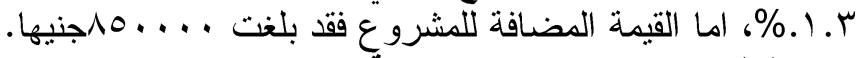

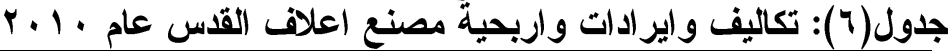

\begin{tabular}{|c|c|}
\hline القيمه بالجنيه & البيان \\
\hline $0 \leqslant \ldots$ & التكاليف الثابتة \\
\hline ro.... & اجمالي التكاليف المتغيرة \\
\hline $19 \ldots$ & اجمالى التكاليف \\
\hline $0 \ldots$ & متو سط الكمية المنتجة \\
\hline$r \leq \ldots$ & متوسط سعر بيع الطن \\
\hline $1, \ldots \ldots$ & اجمالى الاير ادات \\
\hline$r 1 . .$. & صافي العائد \\
\hline 1.5 & نسبة الاير ادات/ التكاليف \\
\hline $10 \ldots$ & القيمة المضافة \\
\hline
\end{tabular}

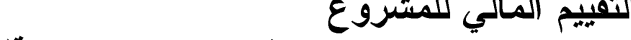

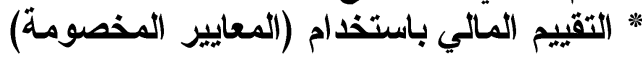

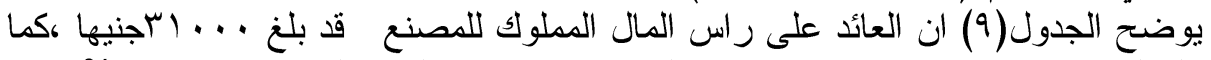

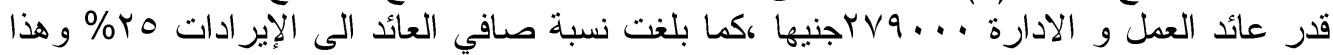

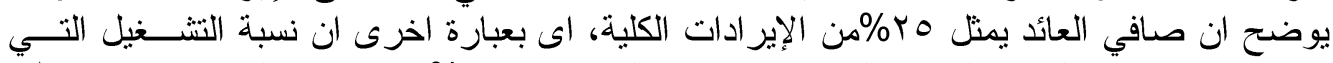

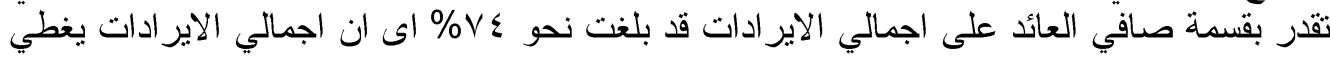

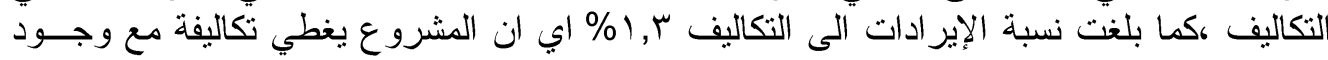

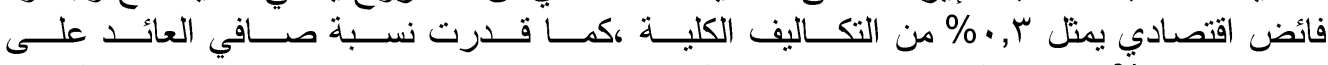

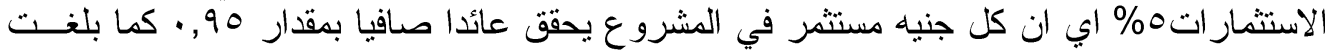

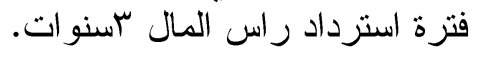

Fayoum J. Agric. Res. \& Dev., Vol. 29, No.2, July, 2015 
$11 \mathrm{~V}$

* التقييم المالي باستخدام (المعايير غير المخصومة)

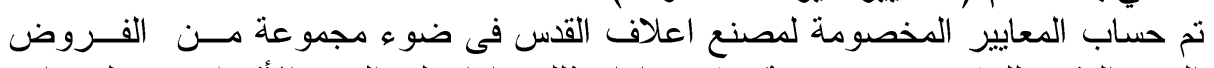

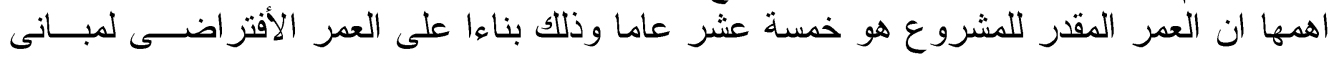

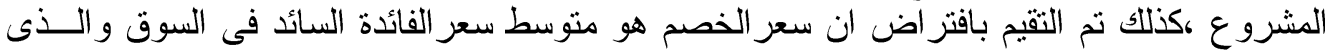

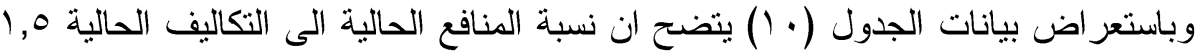

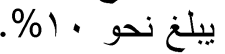

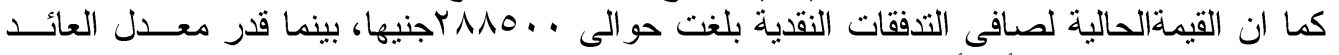

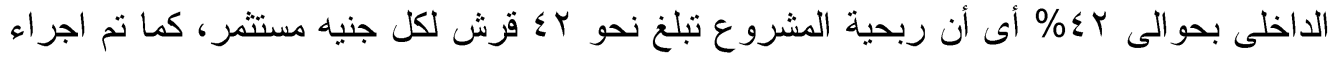

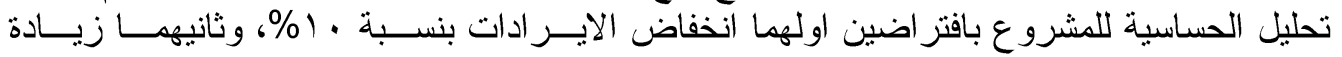

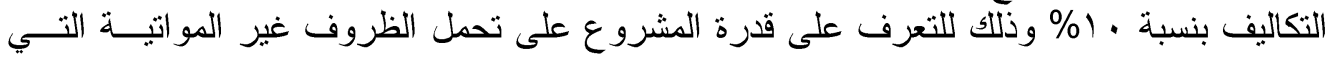

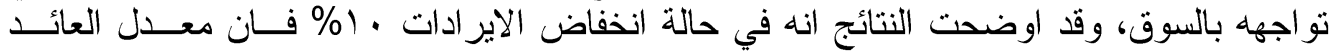

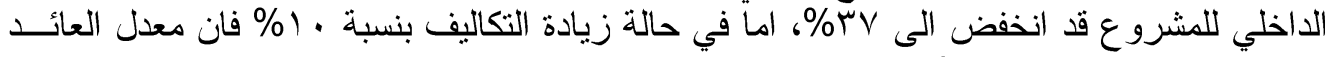
الداخلي قد انخفض الى ع ع\% مما يدل على شدة حساسية المشرو ع لزيادة التكاليف. التسويث : ب التيق يتم التسويق مبانشرة للمنتجين او عن طريق تجار التجزئة. ب-مصنع ايجيبث لتصنيع اعلاف الاواجن بالفيوم

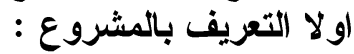

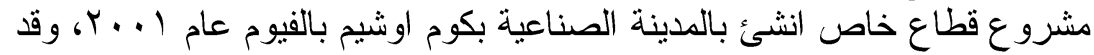

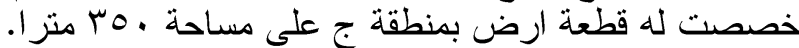

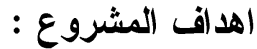
يهدف المشروع لانتاج اعلاف الدواجن لامداد المحافظة باعلاف الدواجن، وتتجيع صناعة

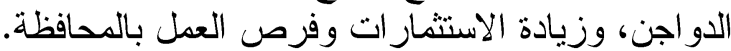

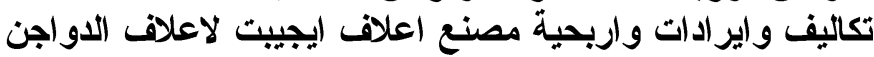

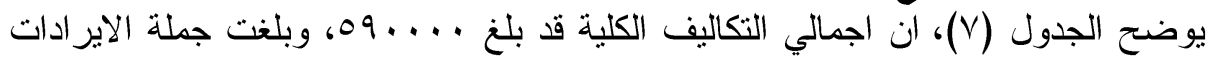

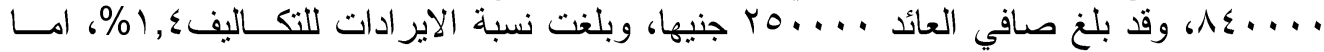

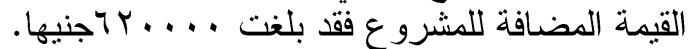

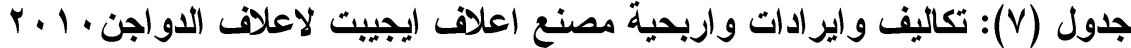

\begin{tabular}{|c|c|}
\hline القيمه بالجنيه & البيان \\
\hline$r v \ldots$. & التكاليف الثابتة \\
\hline rY.... & التكاليف المتغيرة \\
\hline $09 \ldots$ & اجمالي التكاليف \\
\hline ro. & متوسط الكمية المنتجة بالطن \\
\hline$r \varepsilon \ldots$ & متو سط سعر بيع الطن \\
\hline$\wedge \leqslant \ldots$ & اجمالي الاير ادات \\
\hline ro.... & صافي العائد \\
\hline 1.5 & نسبة الاير ادات/ التكاليف \\
\hline Tr.... & القيمة المضافة \\
\hline
\end{tabular}

* التقييم المالي باستخدام (المعايير المخصومة)

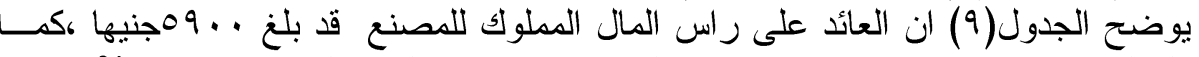

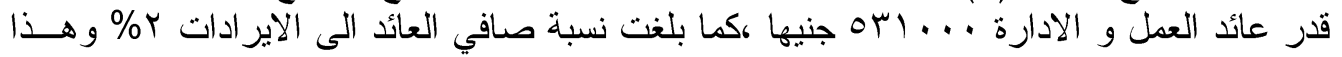

Fayoum J. Agric. Res. \& Dev., Vol. 29, No.2, July, 2015 
111

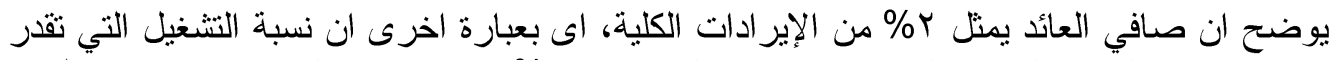

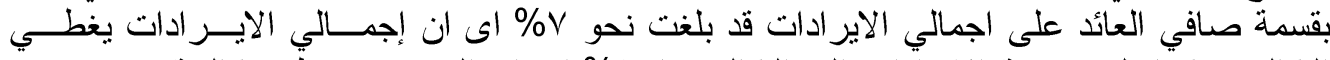

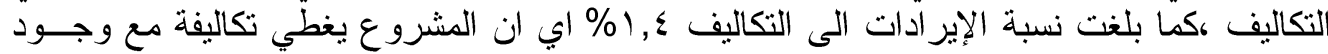

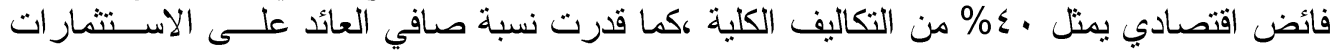

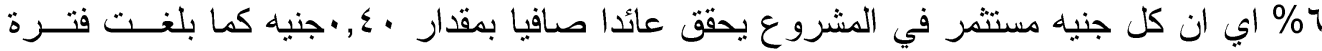

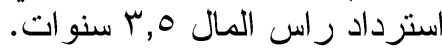

* التقييم المالي باستخدام (المعايير غير المئر المخصومة)

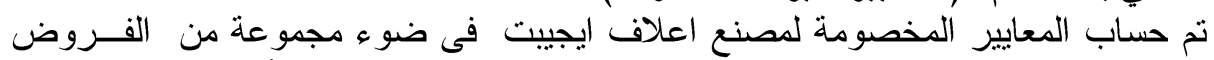

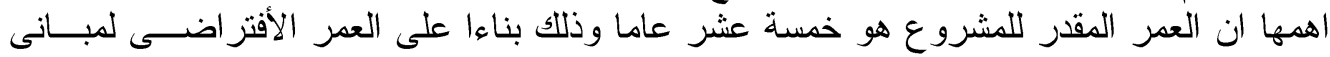

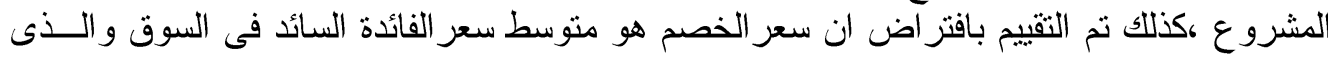

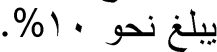

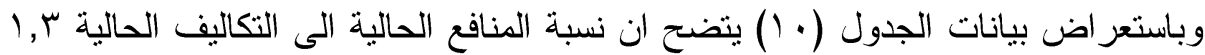

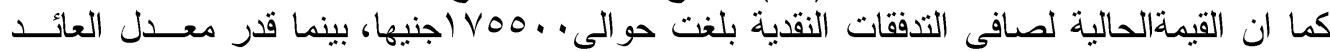

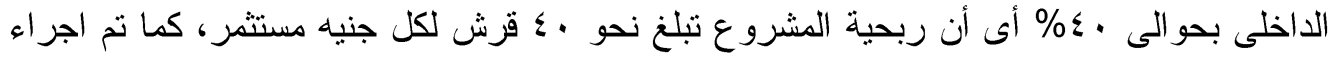

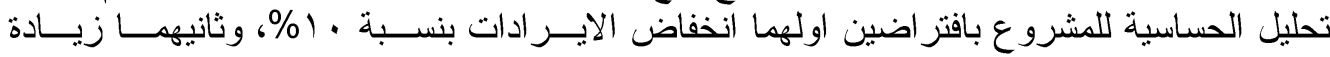

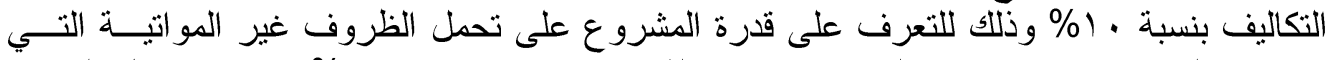

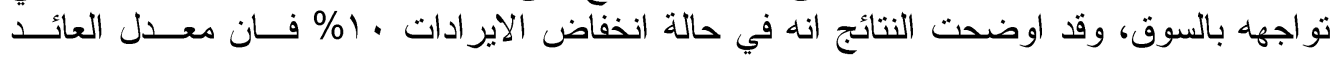

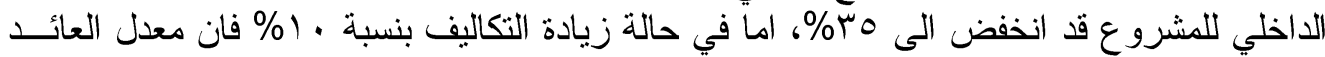

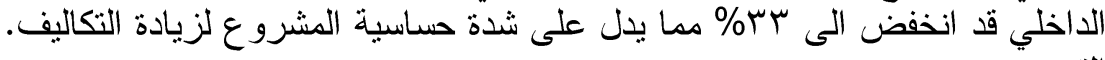

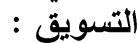
ينتم النسويق مباشرة للمنتجين او عن طريق تجار التجزئة.

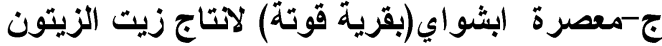

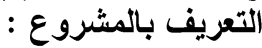
مشروع قطاع خاص انشئ عام 1990 بقرية قو تنة بابشو اي.

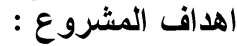

1- يهدف المشروع لتوفير زيت الزيتون بالمحافظة وذلك لتميز المحافظة في انتاج محصول الزيتون.

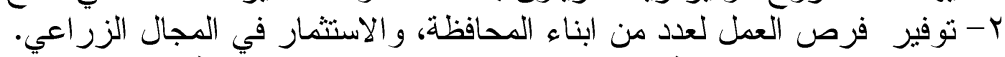

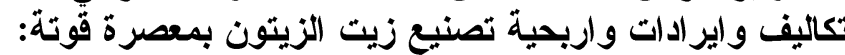

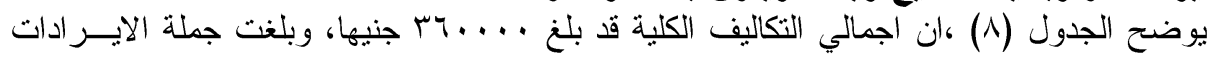

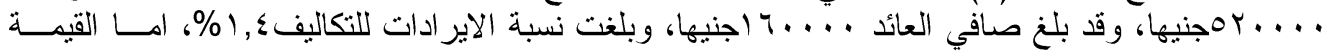

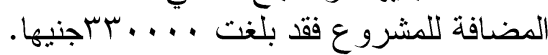

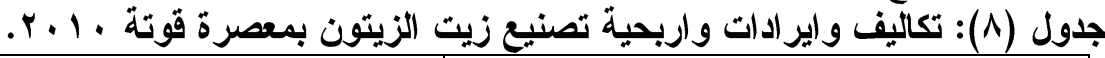

\begin{tabular}{|c|c|}
\hline القيمه بالجنيه & البيان \\
\hline $1 V \ldots$ & التكاليف الثابتة \\
\hline $19 \ldots$ & التكاليف المتغيرة \\
\hline 4ז.... & اجمالى التكاليف الكلية \\
\hline . & متوسط الكمية المنتجة \\
\hline$\varepsilon \ldots$ & متوسط سعر بيع الطن \\
\hline or.... & اجمالي الاير ادات \\
\hline $17 \ldots$ & صافي العائد \\
\hline $1 . \varepsilon$ & نسبة الاير اداتّ/ التكاليف \% \\
\hline 管..... & القيمة المضافة \\
\hline
\end{tabular}

Fayoum J. Agric. Res. \& Dev., Vol. 29, No.2, July, 2015 
* التقييم المالي باستخدام (المعايير المخصومة)

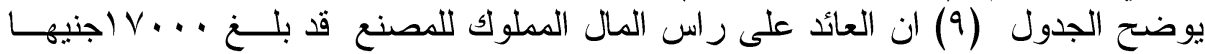

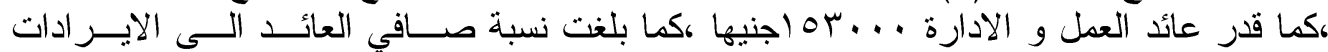

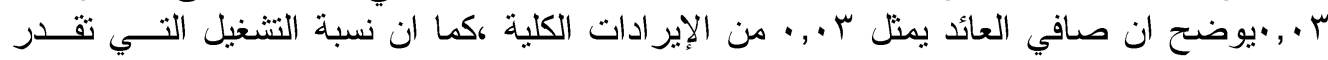

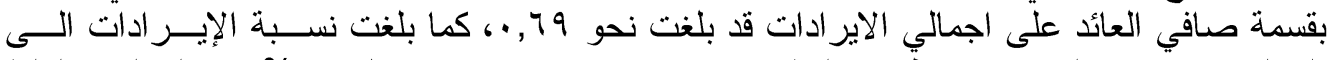

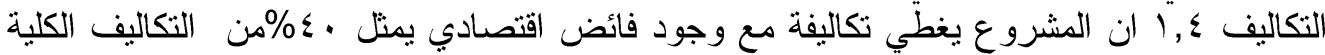

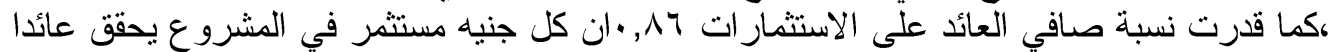

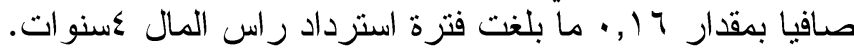

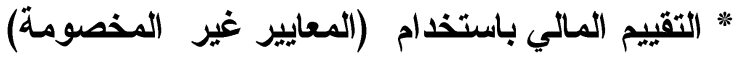

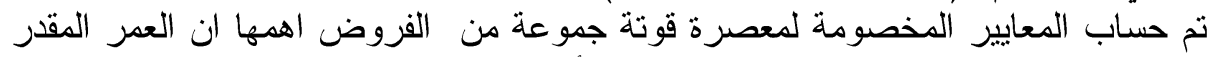

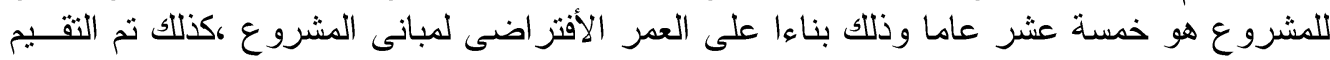

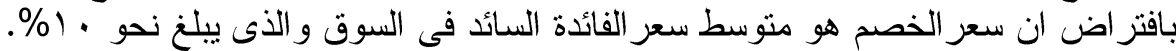

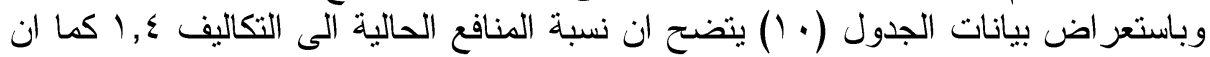

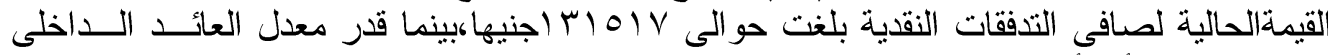

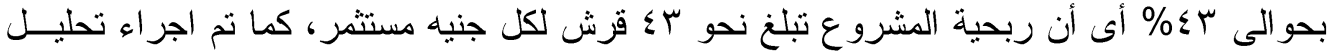

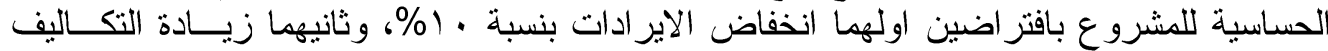

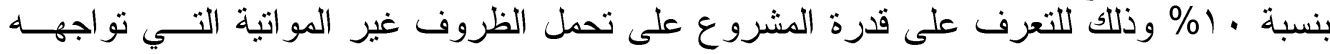

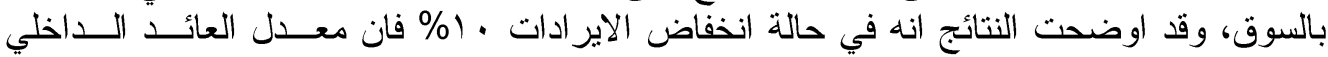

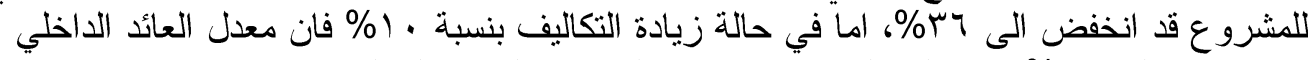

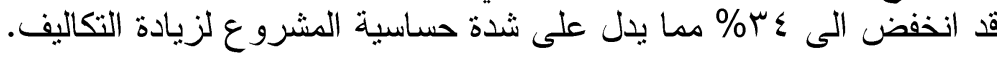

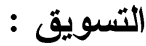

ينت النسويق مباشرة للمستهلكين عن طريق منفذ البيع بالمعصرة، او عن طريق تجار التجزئة.

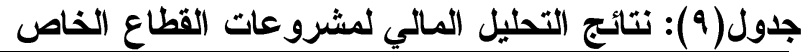

\begin{tabular}{|c|c|c|c|c|}
\hline الوحدة & معصرة قوتة & مصنع ايجيبت لانتاج الدواجن & مصنيع القلاس لاعلاف & المعيار \\
\hline الجنية & $I V \ldots$ & $09 \ldots$ & $\mu \ldots$ & العائد على راس المال \\
\hline الجنية & $104 \ldots$ & or I.... & rvq... & عائد الآدارة \\
\hline$\%$ &..$\cdot r$ &..$r r$ &. Y. & نسبة العائد الى الاير ادات \\
\hline$\%$ &. .79 & $\therefore V$ & $\cdot . V \leqslant$ & نسبة التشغيل \\
\hline$\%$ & $1 . \varepsilon$ & 1.2 & $1 . r$ & نسبة الاير ادات للتكاليف \\
\hline$\%$ &. .14 &. .7 &. .0 & العائد على الاستثمار \\
\hline 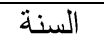 & $\varepsilon$ & $r .0$ & $r$ & فتزرة الاستردداد \\
\hline
\end{tabular}

Fayoum J. Agric. Res. \& Dev., Vol. 29, No.2, July, 2015 
IY.

\begin{tabular}{|c|c|c|c|}
\hline معصرة قوتة & اعلاف ايجيبت & القدس اعــــلاف & البيان ( • (1): نتائج التحليل المالي المعاييز المخصر \\
\hline $\begin{array}{l}1, \varepsilon \\
1+101 \mathrm{~V} \\
\varepsilon r\end{array}$ & $\begin{array}{l}1, r \\
1,00 \ldots \\
\varepsilon\end{array}$ & $\begin{array}{l}1,0 \\
r \wedge \wedge 0 \ldots \\
\leqslant r\end{array}$ & 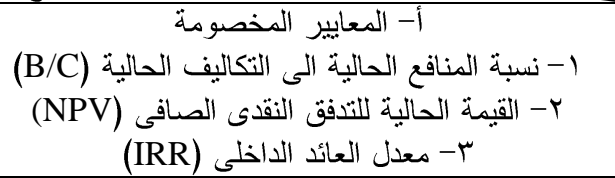 \\
\hline 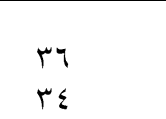 & 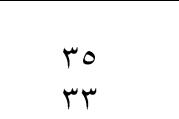 & $\begin{array}{l}r v \\
r \varepsilon\end{array}$ & 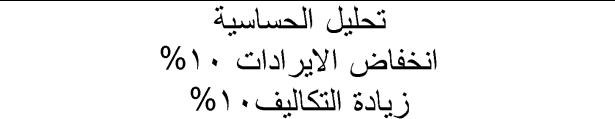 \\
\hline
\end{tabular}

0- أهم المشكلات التى تواجه مشروعات القطاع الخاص:

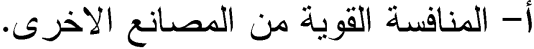

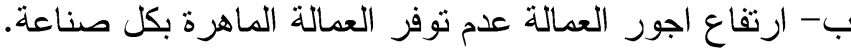

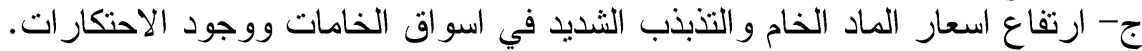
د- ارتفاع الفائدة المحددة لاقر اض المشرو عات الخاصة من الجهات المختلفة.

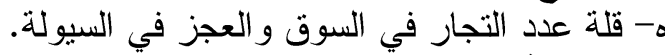

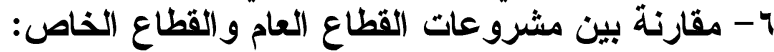

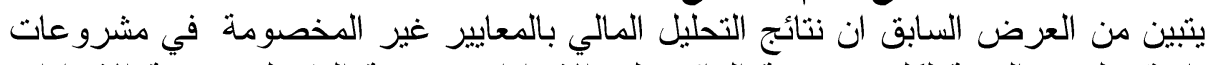

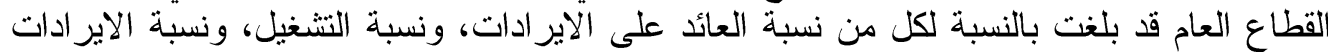

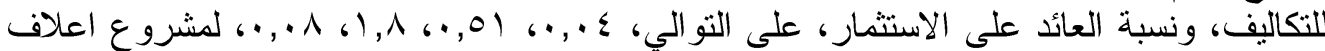

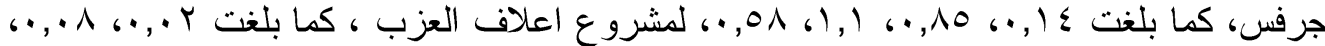

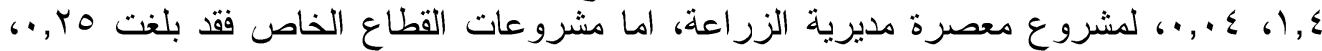

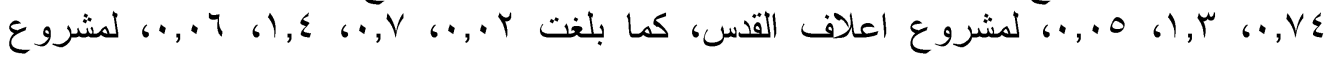

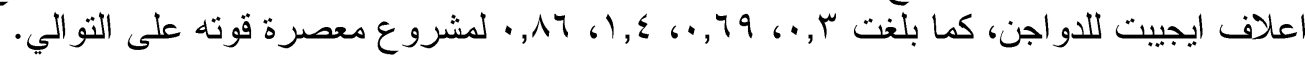

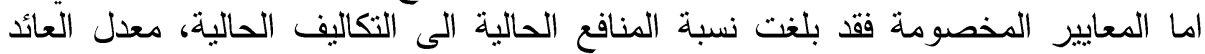

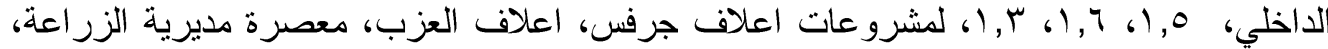

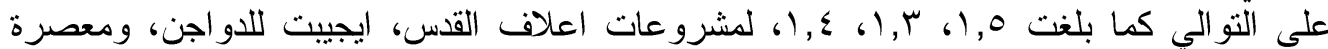

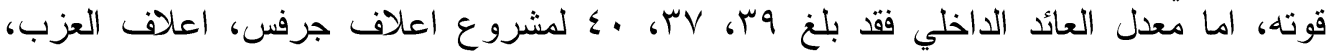

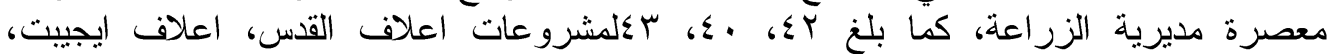

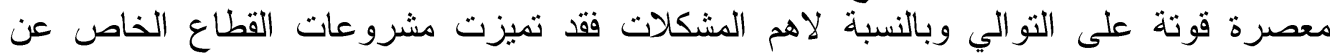

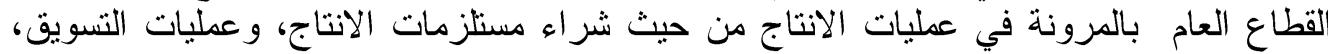

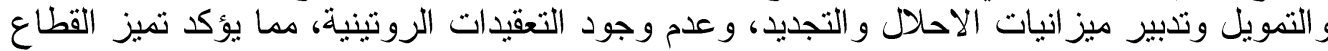

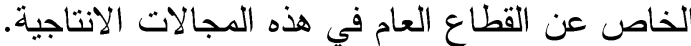

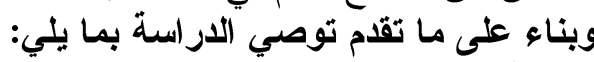

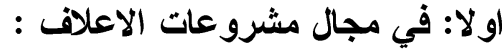

ا- حفز المصانع للعمل بكامل طاقتها لزياددة المنتج المحلي من الاعلاف المات المصنعة ورفع جودتها

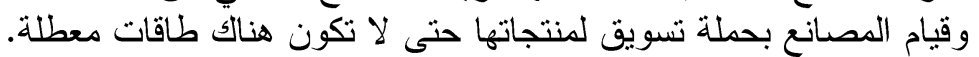
r- البحث عن دول جديدة لاستير اد الحبوب العلفية مع المحافظة على الاسواق الحالية.

Fayoum J. Agric. Res. \& Dev., Vol. 29, No.2, July, 2015 


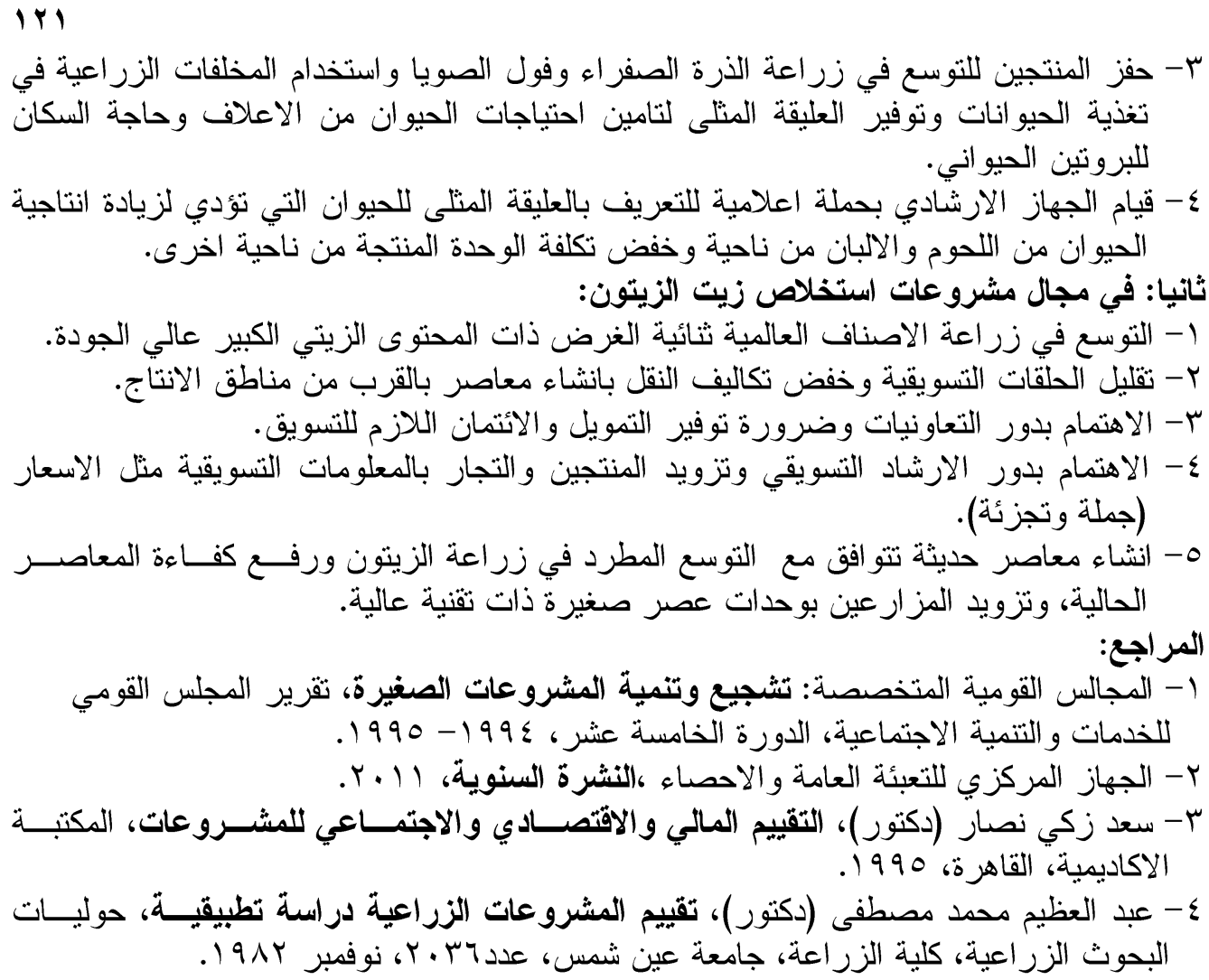

\section{An Economic Study to Evaluate Performance of the Most Important Small Scale Agricultural Industrialization Project in Fayoum Governorate}

Prof. Dr. Abd-Elazeem Mohammed Mostafa*, Prof. Dr. Enas El-Sayed Sadeq* Professor of Agricultural Economic ${ }^{*}$

\section{Dr. Noha Ezzat Tawfeeq**}

\section{SUMMARY}

Researcher

Many third world countries have spent along time in developing the small enterprises because of their importance as a source of labor and offfarm income - there are still many shortages in development policies of these industries in the Arab Republic of Egypt.

The stdy in first part of it is to identify the study population and social characteristics, also in the second part case study and evaluation to some small projects in fayoum the obtained results revealed that ;

The capital return, management return, benefit cost ratio, investment return, bay back period, , respectively is, 1755872, 1220208, 1.6, 0.61, 4 to garfas project, 905505,180505, 1.2, 0.2,3 to,azab project,

Fayoum J. Agric. Res. \& Dev., Vol. 29, No.2, July, 2015 


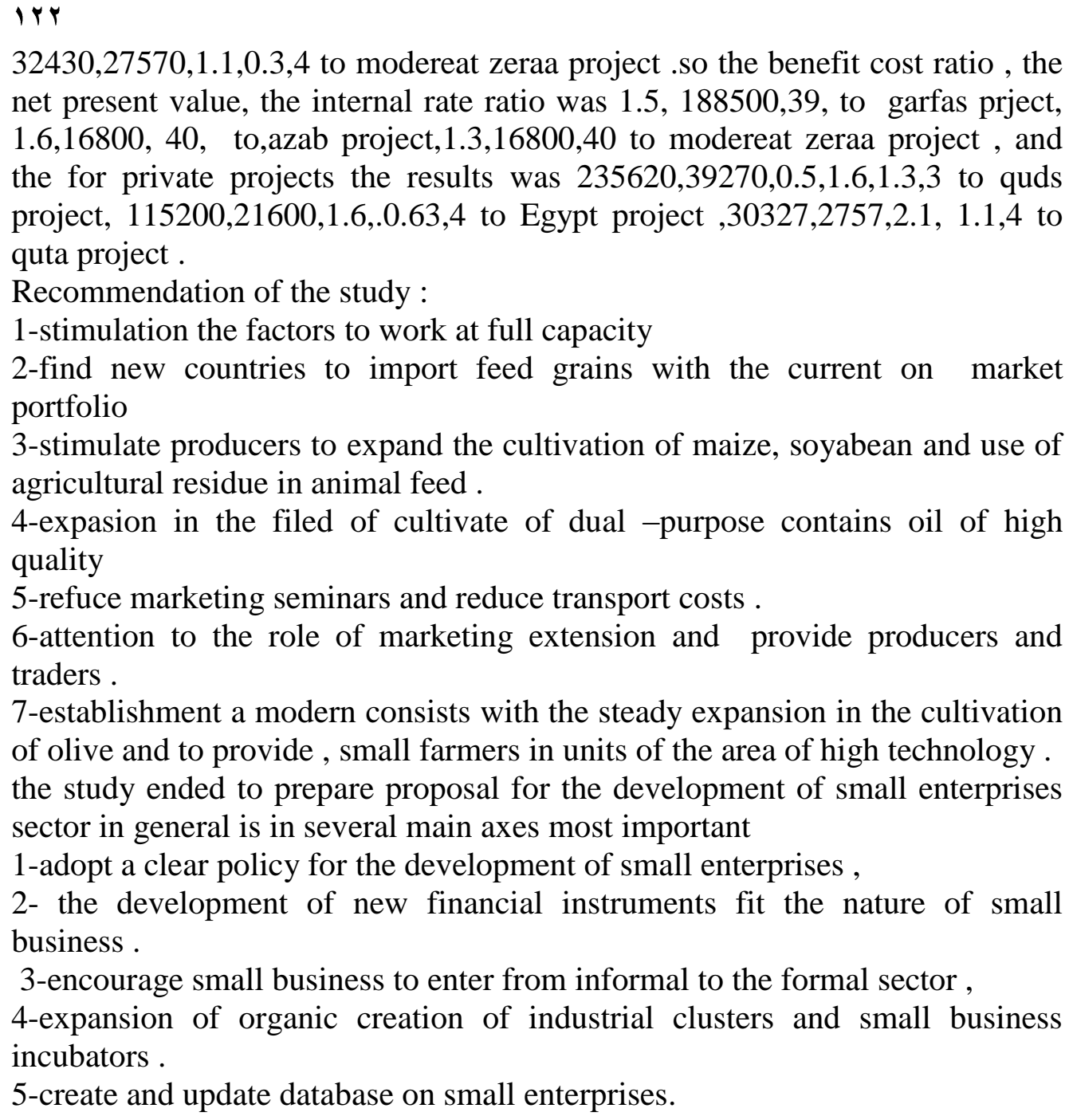
net present value, the internal rate ratio was $1.5,188500,39$, to garfas prject, $1.6,16800,40$, to,azab project,1.3,16800,40 to modereat zeraa project , and the for private projects the results was 235620,39270,0.5,1.6,1.3,3 to quds project, $115200,21600,1.6, .0 .63,4$ to Egypt project ,30327,2757,2.1, 1.1,4 to quta project .

Recommendation of the study :

1-stimulation the factors to work at full capacity

2-find new countries to import feed grains with the current on market portfolio

3-stimulate producers to expand the cultivation of maize, soyabean and use of agricultural residue in animal feed .

4-expasion in the filed of cultivate of dual -purpose contains oil of high quality

5-refuce marketing seminars and reduce transport costs .

6-attention to the role of marketing extension and provide producers and traders .

7-establishment a modern consists with the steady expansion in the cultivation of olive and to provide, small farmers in units of the area of high technology . the study ended to prepare proposal for the development of small enterprises sector in general is in several main axes most important

1-adopt a clear policy for the development of small enterprises ,

2- the development of new financial instruments fit the nature of small business .

3-encourage small business to enter from informal to the formal sector, 4-expansion of organic creation of industrial clusters and small business incubators .

5-create and update database on small enterprises.

Fayoum J. Agric. Res. \& Dev., Vol. 29, No.2, July, 2015 